\title{
Assessment of Training and Development Practices in Xyz Gold Mines Limited (Xyzgml) In Ghana
}

\author{
Francis Eduku \\ Human Resource Practitioner \\ University of Cape Coast, School of Business \\ Department of Management Studies. College of Humanities and Legal Studies \\ Cape Coast, Ghana \\ Elizabeth Annan-Prah, \\ Lecturer University of Cape Coast. School of Business \\ Department of Management Studies. College of Humanities and Legal Studies \\ Cape Coast-Ghana
}

\begin{abstract}
This study assessed the effectiveness of training and development (T\&D) in XYZ Gold Mines Limited (XYZGML). The census method was employed as the study was targeted at 53 junior staff employees who participated in engineering training programmes between July to September 2009; and 9 direct supervisors. Questionnaires were used to collect data for the study. The findings indicate that knowledge and skills level of trained staff in terms of engineering principles, techniques and practices increased after the training programme. However, the results showed that supervisors failed to review their performance regularly and were also not provided the needed feedback to improve their performance. The absence of a recognition scheme to reward trained employees militated against the learning transfer. In spite of these challenges, the training led to significant and moderate improvement in employees' job performance. The study recommends that XYZGML develops a detailed procedure on training transfer; design and implement both financial and non-financial recognition schemes to reward supervisors and trainees who consistently demonstrate the new knowledge and skills on the job; and ensure trainees and their supervisors sign training performance contract specifying performance standards and expectations.
\end{abstract}

Key words: Training, development, training needs assessment, knowledge, skills, and abilities (KSAs), Kirkpatrick's training model.

\section{INTRODUCTION}

The constant change in the workplace has created the need for organisations to continuously provide their employees with certain knowledge, skills, abilities, and other characteristics (KSAOs) in order to maintain market competiveness and business survival (Lee \& Bruvold, 2003; Buckley \& Caple, 2007; Jamil \& Som, 2007). Effective training and development (T\&D) which aims at updating the knowledge, skills, abilities (KSAs) and perspectives of new employees as well as existing workforce on regular basis has been identified as the only best way to facilitate the ongoing change in the workplace (McArdle, 2007; Moskowitz, 2008). According to Tung-Chun (2001), educated and well-trained employees are prerequisites for an organisation's competitive advantage. Given its increasing critical role, organisations now invest heavily in the T\&D of their workforce (Kraiger, McLinden\& Casper, 2004; Merriam \& Leahy, 2005). 
In 2006, organisations in the United States alone spent over $\$ 129$ billion on employee training and development (ASTD, 2007). This investment increased to about \$134 billion in 2007 (Paradise, 2008). A recent study of 15 mining companies in 10 countries also indicated that Ghanaian mining companies spend an average of $\$ 273$ annually in training a machine operator (Swann Global, 2009). These investments clearly emphasise the value that organisations place on their human resources as the key source of sustainable competitive advantage (Noe, 2005; McKenna \& Beech, 2008; Torrington \& Hall 2008; Opperman \& Meyer, 2008).

The significant investment in $T \& D$ by organisations also stems from the belief that $T \& D$ enhances individual and organisational performance (Kearns, 2000; Thorne \&Machray, 2000; Harrison, 2005). T\&D activities enable corporations to achieve their vision, mission, and company-wide strategic goals by facilitating positive changes in employees' knowledge, skills, attitudes, and behaviours that improve individual job performance and contribute to the overall effectiveness of organisations (Moskowitz, 2008). Additionally, effective T\&D has the associated benefits of increased profits, higher productivity rates, lower turnover rates, improved team and individual performance, and increased company loyalty (Hughey \& Mussnug, 1997; Burden \& Proctor, 2000; Armstrong, 2001;Aguinis \& Kraiger, 2009). Individual employees also benefit from T\&D through self-empowerment and lifelong learning (Wall, Wood \& Leach, 2004; Nickson, 2007). Thus, employee T\&D is now a big business and almost every organisation, city and state has become involved in job training (Goldstein \& Ford, 2002).

In spite of the tangible and intangible benefits associated with $T \& D$, many analysts of $T \& D$ programmes contend that much of the money being spent on employee T\&D efforts is not being well spent. This is because most organisations neither assess their T\&D needs adequately nor evaluate the benefits of training to organisations (Goldstein \& Ford, 2002; Noe, 2005; Brinkerhoff, 2005). Such conclusions have led to widespread perceptions and criticisms that T\&D are expensive activities (Gómez-Mejía, Balkin, Cardy, 2010). Consequently, organisational T\&D activities are normally treated as optional schemes and not a strategic activity (White, 1998).

The whole area of employee T\&D presents both an opportunity and a challenge for organisations. It presents an opportunity for organisations to leverage their T\&D practices to improve the KSAs of their employees and the challenge of ensuring that learned knowledge and skills successfully transfer to the job environment to improve the overall effectiveness of organisations.

Using Kirkpatrick's Level 2 (learning) and Level 3 (behaviour) training evaluation model, this study strives to contribute to the area of employee T\&D by investigating the effectiveness of training and development programmes for junior staff being undertaken by XYZ Gold Mines Limited (XYZGML). In this regard, the extent to which trainees attitudes' changed, knowledge and skills increased as a result of attending the training programme (Level 2) were assessed, as well as the extent to which their performance on the job improved following participation in the training programme (Level 3) (Kirkpatrick, 2007).

\section{STATEMENT OF THE PROBLEM}

Evidence from benchmarking studies by the American Society for Training and Development (ASTD) suggests that organisations are investing more heavily in the T\&D of their employees (Van Buren \& Erskine, 2002; Moskowitz, 2008). As a result of the significant investment, it is important that the T\&D efforts demonstrate a convincing value-addition to organisations 
(Dowling \& Welch, 2004; Noe, 2005).Additionally, since the desired outcome of any T\&D activity is improved performance, it is inadequate if T\&D efforts do not produce significant new behaviours in the workplace (Wang \&Wentling, 2001; Goldstein \& Ford, 2002).

However, researchers have shown that only about $10 \%$ to $40 \%$ of training provided transfers to the job environment (Broad \&Newstrom, 1992; Holton \& Baldwin, 2003; Merriam \& Leahy, 2005). Following the commissioning of its Sulfide Expansion Project in 2007, XYZGML has initiated a number of T\&D activities at the mine. From 2006 to 2009, over two hundred junior staff employees have benefited from various engineering training programmes at the AngloGold Training Centre, Obuasi. Although XYZGML is putting in much effort towards the $T \& D$ of its junior staff workforce, no formal training evaluation has been conducted to assess the effectiveness of these programmes. The question therefore is "how effective have these junior staff engineering T\&D programmes been in achieving their specific objectives?"

The study, therefore, was guided by four research questions as follows:

1. To what extent did the T\&D programmes increase the knowledge and skills level of employees participating in company-sponsored training programmes?

2. To what extent have employees transferred the knowledge and skills they acquired from company-sponsored training programmes to the job?

3. What factors hindered the application of knowledge and skills gained through the T\&D to the workplace?

4. To what extent have the T\&D programmes resulted in positive changes in employee performance on the job?

\section{METHODOLOGY}

This study employed a descriptive cross-sectional survey design (Creswell, 2008). To achieve the study objective, data was collected on training participants' perceptions and opinions about the programme, their learning experiences and their job behaviours after the T\&D programme. The population of the study comprised 909 employees of XYZGML. Out of this total, 63 represent management, 158 senior, and 688 junior staff. However, the target population for the study comprised 53 junior staff employees of the Plant and Mine Maintenance departments who participated in the engineering training programmes from July 2014 to September 2014 and all the 9 direct supervisors of those employees. This study employed the census method as the study population was small. Questionnaires were used to collect data from the study population. Two sets of questionnaires were used for the study: one for the training participants and the other for the direct supervisors of the training participants. The questionnaires were adapted from Kirkpatrick and Kirkpatrick's (2007) practical guide for evaluating training programmes but were modified to suit the research questions of the study. Closed-ended questions and scale items were used to collect data from respondents. The validity and reliability of the questionnaires designed for the study were pre-tested with 10 training participants from the Plant Maintenance Department and 5 training participants from the Mine Maintenance Department.

\section{The concept of training}

\section{LITERATURE REVIEW}

On a very general level, training can be described as a process of providing job-related competencies to employees to enable them to perform their current jobs effectively. Training has also been defined as a planned effort whereby an organisation helps its employees acquire job-related knowledge, skills, abilities, and behaviours to improve their performance on the job (DeCenzo \& Robbins, 1998; Bohlander \& Snell, 2004; Noe et al., 2006). Therefore, training 
programmes are planned to produce a more competent technician in the workplace or leaders of complex organisations (Goldstein \& Ford, 2002; Armstrong, 2006). Non-managers are normally trained in their current jobs to develop technical skills and competencies (Stoner, Freeman \& Gilbert, 1995; Eugine, 2003). In some literature, training is used synonymously with development

\section{The concept of employee development}

The concept of employee development has engaged the concern of experts and practitioners. Development has been conceptualised as a process whereby an employee through learning and maturation becomes increasingly complex, more elaborate and differentiated, and able to adapt to the changing business environment (Beardwell \& Holden, 1997; Beardwell \& Claydon, 2007). It also encompasses the whole change of the employee in the course of their experience and growth through career and lifespan (Gibb, 2002; Harrison, 2005). The individual employee, through development process, improves their abilities to perform a wide variety of roles within and outside the organisation as well as enhancing their adaptability in work performance both in the short-term and the long-term (Mumford \& Gold, 2004; Wilson, 2005; Armstrong, 2006). Development activities therefore seek to prepare employees for the next job opportunity (Noe, 2005; Werner \& DeSimone, 2006; Moskowitz, 2008).

Thus, in the workplace, employees are trained and managers and professionals are developed (Gibb, 2002). Development programmes emphasise on personal development and planned learning from experience (Armstrong, 2006) and also purport to enhance the ability of the employees to advance in the company (Eugine, 2003).

\section{Business case for training and development in organisations}

Training plays a pivotal role in organisational functioning (Goldstein, 1993). According to O'Toole and Lawler (2006), understanding the phenomenon of employee training and development (T\&D) requires the appreciation of the following changes that take place as a result of learning: rapid changes in technology, job exploration, downsizing, global competition and aging workforce. As the generator of new knowledge, employee T\&D is placed within a broader strategic context of human resources management with the goal of benefiting both the organisation and employees (Vemic, 2007). Benefits for the organisation include improved employee work performance, increased productivity, decrease in wastage, fewer accidents, less absenteeism, and greater customer satisfaction (Aquinas, 2006; Buckley \& Caple, 2007). Individual employees also benefit from company-sponsored training through intrinsic job satisfaction (performing tasks well) and extrinsic job satisfaction derived from extra earnings accrued through improved performance and enhancement of career and promotion prospects within and outside the organisation (Buckley \& Caple, 2007). The strategic context of T\&D also extends to a wide range of learning actions from training for tasks and knowledge sharing to improved customer service and career development (Noe, 2005, Beardwell \& Claydon, 2007). T\&D efforts enable organisations to increase their competitiveness and ensure their survival in the face of constant change in the workplace (Jamil \& Som, 2007; Moskowitz, 2008; Aguinis \& Kraiger, 2009).

Additionally, changes in work systems, technological developments, and new services continue to create obsolescence in the workplace. Obsolescence results when employees no longer possess the knowledge and skills needed to perform successfully on the job (Werther \& Davis, 1996). However, training and developing employees leads to increased employee satisfaction and commitment, improves operational flexibility by extending the range of skills possessed by 
employees (Armstrong, 2001), and strengthens the organisation's competitiveness (Hughey \& Mussnug, 1997; Burden \& Proctor, 2000).

Furthermore, training-related changes result in improved job performance and other positive changes like acquisition of new skills and knowledge (Hill \& Lent, 2006; Satterfield \& Hughes, 2007) that serve as antecedents of job performance (Kraiger, 2002). Thus, T\&D activities do not only enable corporations to achieve their vision, mission, and company-wide strategic goals but facilitate positive changes in employees' knowledge, skills, attitudes, and behaviours that improve individual job performance and contribute to the overall effectiveness of organisations (Moskowitz, 2008, Opperman \& Meyer, 2008).

\section{Training and development needs assessment}

A training needs assessment (TNA) is a process of determining whether training is the right solution to a workplace problem (Tobey, 2005; Mathis \& Jackson, 2007; Cekada, 2010). It is the gap between the knowledge, skills and attitudes (KSAs) already possessed by the trainee (Rao, 2005). TNA is therefore the first step in the training and development process (Elkeles \& Phillips, 2007; Kirkpatrick \& Kirkpatrick, 2007; Opperman \& Meyer, 2008), and the basis for the training plan (Van der Wagen, 2007). In order to be successful and achieve their objectives, each type of T\&D initiatives must target a certain training need (Bhattacharyya, 2007; McArdle, 2007). This need must always be linked to the essential knowledge, skills and attitudes (KSAs) that individuals must possess to perform their jobs competently thereby accomplishing the desired results (Opperman \& Meyer, 2008). It is believed that TNA not only ensures returns on investments on T\&D by organisations, but also as the first step of T\&D cycle, it minimises errors possibly made in the training programmes (Elbadri, 2001). A considerable relationship is also claimed to exist between TNA and training effectiveness (Tung-Chun, 2001). TNA also serves as the foundation for determining instructional objectives, the selection and design of instructional programmes, the implementation of the programmes and the evaluation of the training provided (Miller \& Osinski, 2002).

However, many organisations fail to acknowledge the importance of TNA in practice (Jamil \& Som, 2007). Researchers have shown that approaches to T\&D are often conducted informally and unsystematically with most organisations relying heavily on top management judgements to make training decisions such as types of training to invest in and which employees to receive training (Agnaia, 1996; Elbadri, 2001; Gargiulo et al; 2006; Buckley \& Caple, 2007).

To be effective, TNA must be conducted at three levels of analysis, namely: organisational analysis, task analysis, and person analysis (Miller \& Osinski, 2002; Noe, 2005; Mathis \& Jackson; 2007; Dessler, 2008). While any one of the three levels of analysis might indicate a need for training, it is recommended that information from all three levels of analysis are collected before a decision to devote time and money for training is made (Noe, 2005).

Methods of training have been presented in a lot of papers and we will not dwell on that. The next section discusses transfer of training.

\section{Transfer of training}

According to Broad and Newstron (1992), training transfer refers to "the effective and continuing application, by trainees to their jobs, of knowledge and skills gained in training both on and off the job" (p.6). Holton III and Baldwin (2003), on the other hand, define transfer as the degree to which employees use newly acquired knowledge and skills to perform their job effectively and enhance organisational effectiveness. It has been widely acknowledged 
that training transfer is important for organisations to ensure that training leads to desired work outcomes such as improvement in knowledge and skills and increased job performance (Goldstein \& Ford, 2002; Noe, 2005; Velada et al., 2007).

Nevertheless, researchers have acknowledged that transfer problems always occur when training employees (Broad \& Newstron, 1992; Rouiller \& Goldstein, 1993, Montesino, 2002). For instance, Broad and Newstron (1992) identify the following four barriers that inhibit the transfer of the newly acquired knowledge and skills back to the job: (1) lack of involvement by top management in the behaviour change process; (2) lack of reinforcement on the job to support trainees in applying knowledge and skills to their jobs; (3) interference by the immediate environment (work and time pressures, insufficient authority, ineffective work processes, inadequate equipment or facilities), and (4) lack of active support by the organisational climate or culture.

\section{Kirkpatrick's model of evaluating training and development}

A number of scholars have developed models of evaluation at some point in time, however the Kirkpatrick's evaluation framework has been articulated as the most influential and widely used framework for evaluating T\&D efforts in organisations (Phillips, 1997; Goldstein \& Ford, 2002; Noe, 2005; Truelove, 2006; Beardwell \& Claydon, 2007), which this study adopts. The widely acceptance of the Kirkpatrick evaluation model was confirmed in 1997 when the American Society for Training and Development (ASTD) assessed the nationwide prevalence of the importance of measurement and evaluation to HRD executives by surveying a panel of 300 HRD executives from various U.S. organisations. Survey results indicated that the majority (81\%) of the HRD executives attached some level of importance to evaluation and over half (67\%) used the Kirkpatrick Model (ASTD, 1997). According to Beardwell and Claydon (2007), the Chartered Institute of Personnel and Development (CIPD) 2006 Learning and Development survey revealed the pervasive usage of the Kirkpatrick's training evaluation model: 98\% evaluate at Level 1, 75\% at level 2, 62\% at Level 3, and 36\% evaluate as far as Level 4.

The Kirkpatrick Model has also been the foundation on which subsequent models for evaluating training and performance are built (Russ-Eft \& Preskill, 2001). Truelove (2006) concludes that the model has endured because it is simple, logical, and useful. Bee and Bee (2003) also believe that the Kirkpatrick Model is useful because each evaluation level contributes to building up a complete picture of the whole T\&D evaluation process. Popularly known as the four-level model, Kirkpatrick's hierarchical model has the following components: reaction (level 1), learning (level 2), behaviour (level 3), and results (level 4) (Kirkpatrick, 1994).

Bates (2004) posits that there are at least three limitations of the Kirkpatrick Model that have implications on the ability of training evaluators to deliver training benefits to organisational clients. These limitations include the incompleteness of the model, the assumption of causality, and incremental importance of information. Despite the foregoing criticisms and limitations of the Kirkpatrick four-level training evaluation model, the model has dominated the evaluation literature.

\section{Results}

\section{RESULTS AND DISCUSSION}

The key results that emerged from research objective 1 are that majority of the employees (64.1\%) confirmed that they had little knowledge prior to the training. The knowledge and 
skills level of employees were confirmed by $77.8 \%$ of supervisors who acknowledged that their subordinates had little knowledge and skills level before their participation in the training programme. However, employees' knowledge and skills level improved after the training. This was confirmed by $32 \%$ of the employees who indicated their knowledge level was very high after the training, and 49.1\% acknowledging high level of knowledge and skills after the training. Increase in employees' level of knowledge after the training was also confirmed by $11.1 \%$ of the supervisors as very high and $66.7 \%$ indicated high level of knowledge after the training.

With regard to research objective 2, the following were the key results. Twenty-four (45.3\%) of employees reported that they were not given the opportunity to use the new knowledge and skills gained through the training on the job. In contrast, however, $20(37.8 \%)$ of the employees confirmed that they were given the required opportunity to utilize the newly acquired knowledge and skills on the job. Eight out of the 9 supervisors (88.9\%), on the other hand, reported that their subordinates (being the trained employees) were offered the needed opportunity to experiment the new knowledge and skills acquired from the training on the job. Working tools to enable trained employees to perform their assigned responsibilities were found to be either non-existent or inadequate. Thirty-two employees $(60.3 \%)$ out of the 53 surveyed attested to this weakness in the company and was confirmed by $22.2 \%$ of their supervisors. Twenty-five (46.9\%) of the trained employees submitted that their performance after training was not regularly reviewed and were also not provided the required feedback on their performance. On the contrary, however, $36.2 \%$ of the trained employees indicated that their performance after training were reviewed regularly and also received regular feedback on their performance. All the nine supervisors (100\%) agreed strongly or agreed that they reviewed their subordinates' performance and provided regular feedback on their performance to them. There is no scheme in place to reward employees who consistently apply the new knowledge and skills gained through the training to the job. Forty-eight of the trained staff $(90.6 \%)$ stated that there was no reward scheme in place for employees who continuously demonstrated the new competencies acquired from the training on the job, and $88.9 \%$ of the supervisors acknowledged this reality. However, both supervisors (66.7\%) and employees $(90.6 \%)$ agreed strongly or agreed that trained staff who failed to consistently apply the new competencies gained through the company-sponsored training to the job were sanctioned.

The key results highlighted in the study under research objective 3 were that the company has implemented monitoring mechanisms to evaluate employees' performance on the job after training. The on-the-job performance of the majority of the trained staff $(41.5 \%)$ improved significantly after the training programme. Majority of the supervisors (44.5\%) also confirmed significant improvement in the trained staff's performance after the training. Nineteen employees (35.9\%), however, indicated that they experienced moderate performance improvement after the training, and $22.6 \%$ attested that they experienced little improvement in their job performance after the engineering training programme. The moderate and little performance improvement experienced by the trained staff were also observed by $33.3 \%$ and $22.2 \%$ of their direct supervisors respectively.

\section{Discussion}

The results for research question 1 revealed that training participants' knowledge and skills level improved after the training programme. Thus, trainees absorbed and understood the principles, facts and techniques taught in the course of the training programme (Kirkpatrick, 1994). Learning acquired through the training also improved the theoretical knowledge of trainees (Bee \& Bee, 2003; Werner \& DeSimone, 2006) as well as increasing their skills and 
attitudes (Armstrong, 2001; Goldstein \& Ford, 2002; Gully \& Chen, 2010). However, the slightly mixed results reported by few trainees that there was no change in their knowledge level after participating in the training programme could be linked to Bee and Bee's (2003) interpretation of what is actually meant by learning. According to Bee and Bee (2003), learning evaluation is not an assessment to ascertain whether learning has been transferred to the workplace but rather it seeks to measure what has been learned from the programme. It can therefore be concluded that trainees who indicated that there was no change in their knowledge after the training programme did experience some level of learning but were unable to make a distinction between knowledge transfer to the workplace and theoretical knowledge gained through the training programme.

With regard to research question 2, majority of the training participants and their immediate supervisors agreed that the knowledge and skills acquired from the training programme were transferred to the job. This finding confirms studies conducted by researchers (Rothwell \& Sredl, 1992; Goldstein \& Ford, 2002; Noe, 2005) into training transfer which found that supportive organisation environment such as organisational climate, supervisor support, and co-worker encourages training transfer. Further research studies have also shown that when trainees perceive that their supervisors support the application of newly developed knowledge and skills, they are more likely to transfer these competencies back to the job (Brinkerhoff \&Montesino, 1995; Colquitt et al., 2000; Noe, 2005; Tracey \&Tews, 2005). Clearly, trainees who reported that they applied the new knowledge and skills to the job received the needed support from their immediate supervisors and co-workers. Ford et al (1998) also found that performance self-efficacy, which refers to the individuals' general belief that they are able to change their performance when desired, is strongly related to transfer of training. They observed that trainees with higher self-efficacy are more likely to transfer the training to the job. Contrary to the findings, few of the training participants, on the other hand, reported that they did not continuously apply the knowledge and skills gained from the training to the job. This result could, therefore, be attributed to low self-efficacy on the part of the trainees to apply the new knowledge and skills to the job as well as lack of supervisory support during the application of the new knowledge and concepts to the job after the training programme.

The findings for research question 3 revealed mixed responses from training participants and their immediate supervisors though some of the results supported the findings in the literature. Factors preventing the transfer of training were grouped into supervisory and coworker support. With regard to supervisory support, most of the training participants and their supervisors confirmed that there were no adequate working tools in place to enable the trainees to perform their assigned jobs competently after training. Additionally, recognition for good performance after the training was also non-existent; hence, there was no incentive in place for employees who implemented the knowledge and skills acquired from the training. However, these results are in contrast with findings by Broad and Newstron (1992) who indicated that on-the-job reinforcements initiated by supervisors enable trainees to apply the newly acquired knowledge and skills to their jobs. The finding also contradicts Hale's (2002) observation that to encourage the application of new knowledge and skills to the job, employees must be rewarded for exhibiting the new behaviours.

Regarding the opportunity to use the new knowledge and skills acquired from the training as well as performance feedback provided to trainees, training participants and their immediate supervisors offered contrasting views on the two variables. Whereas the immediate supervisors of training participants agreed that they provided adequate opportunity to their 
subordinates to use the new knowledge and skills on the job and also provided the necessary feedback on their performance, the trainees disagreed with the observation made by their immediate supervisors, thereby contradicting researchers' findings on the effectiveness of these two variables on learning transfer. As noted by several researchers, supervisory support in providing performance feedback and using effective communication practices enhances transfer of learning to the job (Goldstein \& Ford, 2002; Holton \& Baldwin, 2003; Tracey \&Tews, 2005; Chiaburu \& Taklead, 2005). Tracey et al (1995) also found opportunity to use the newly acquired knowledge and skills on the job as one of the indicators of supportive organisational climate that facilitates transfer of training to the workplace.

The disagreement relating to opportunity to use new skills also raises doubts as to whether, indeed, an action plan was developed to guide the training transfer. In spite of the foregoing contradictions in the literature, training participants and their immediate supervisors agreed that action plan was developed to facilitate training transfer and sanctions for nonperformance after participating in a training programme were also in place to support learning transfer. Furthermore, training participants articulated the high level of support received from their co-workers, confirming research findings relating co-worker or peer support as one of the indicators of transfer climate that influences training transfer to the workplace (Rothwell\&Sredl, 1992; Goldstein \& Ford, 2002; Holton \& Baldwin, 2003; Tracey \&Tews, 2005).

Finally, with respect to findings relating to research question 4, study participants indicated that trainees' on-the-job performance improved after their participation in the engineering training programme. This result confirms similar findings by Barber (2004). In a study involving mechanics in Northern India, Barber found that trained mechanics learned to build two Jeep bodies utilizing a home-made hammer, chisel, and oxyacetylene. Other researchers have also found that training-related changes result in improved performance on the job (Kraiger, 2002; Hill \& Lent, 2006; Satterfield \& Hughes, 2007). Similarly, trainees' self-report of performance improvement after training was found by Veladaet al (2007) as the most important and valid source of the measurement of job performance since trainees' perceptions drive their motivation and performance on the job. Thus, trainees' self-report that their performance on the job improved following their participation in the engineering training programme provides enough justification that the changes in their performance were attributable to the new knowledge and skills acquired from the training programme.

\section{CONCLUSIONS}

The extent to which trained employees transfer the newly acquired knowledge, skills and abilities back to the job is critical for the success of any training intervention designed to rectify knowledge or performance deficiency identified through training needs assessment. Such successful transfer of learning will indeed be facilitated by a supportive organisational environment consisting of appropriate organisational climate, supervisor support as well as co-worker support.

With regard to this study, knowledge and skills level of trained staff in terms of engineering principles, techniques and practices increased after the training programme. However, the required organisational climate and supervisory support to facilitate the transfer of the new knowledge and skills to the job was lacking, resulting in a controversy between supervisors and their subordinates as to the interpretation of the level of support required and provided. For instance, majority of the trained staff and their supervisors lamented on the lack of working tools to perform assigned duties. Additionally, the trained staff emphasized that their 
supervisors failed to review their performance regularly and were also not provided the needed feedback to improve their performance. Furthermore, the absence of a recognition scheme to reward trained employees who consistently demonstrate the application of the new knowledge, techniques and concepts acquired from the training to the workplace militated against the learning transfer.

In spite of the challenges confronted by trained staff, the training led to significant and moderate improvement in employees' job performance. This significant and moderate improvement in performance notwithstanding, some employees experienced little performance improvement. Overall, the engineering training programme was successful as it resulted in increased knowledge and skills level of employees and also contributed to improved employee performance on the job.

\section{RECOMMENDATIONS FOR POLICY FORMULATION}

The foregoing findings and conclusions point to fundamental concerns that must be addressed to maximise return on training and development efforts in XYZ Gold Mines Limited (XYZGML). It is recommended that Management of XYZGML should:

1. Develop a detailed procedure on training transfer. This procedure should specify the responsibilities of management in the areas of required logistics and working tools, supervisory and co-work support. Highlighted in supervisory responsibilities should include but not limited to the development of action plans to support training transfer, regular performance review, feedback, coaching and mentoring. Co-workers should be encouraged to support trained staff and not to undermine their efforts when exhibiting the new competencies on the job.

2. Implement a recognition scheme, both financial and non-financial, to reward both supervisors and trainees who consistently demonstrate/apply the new knowledge and skills on the job respectively.

3. Ensure trainees and their supervisors sign training performance contract specifying performance standards and expectations to eliminate any argument relating to the achievement or non-achievement of the level of performance expected from trainees after the training, and also reduce subjectivity in rating employees' performance level after training.

\section{LIMITATIONS}

The two main limitations inherent in this study are the sample size and the scheduling of participants for training. The study used the census approach due to the small size of the study population. The study population, comprised of fifty-three (53) junior staff employees and all their nine (9) direct supervisors, was surveyed during the research. This limitation has an impact on external validity and makes the results difficult to generalise to other employees in similar or other work settings.

These limitations notwithstanding, the study is important as it hopes to augment the existing body of knowledge and also to raise new aspects for discussion in future research concerning the effectiveness of employees T\&D programmes in organisations. The study therefore seeks to contribute to the theory and practice in the field of HRD of which T\&D constitutes the largest realm (Swanson \& Holton, 2009). 


\section{SUGGESTIONS FOR FURTHER RESEARCH}

To enable generalisation of the findings, it is suggested that this research be replicated in other mining companies. Additionally, some of the issues identified in this study can be used as a focus of future research, particularly issues relating to training transfer. Further research may also consider factors that facilitate training transfer in the workplace. Finally, it is suggested that future studies in either private or public organisations in relation to T\&D activities should consider implementing the full training evaluation model conceptualised by Kirkpatrick as follows: Level 1 (reaction), Level 2 (learning), Level 3 (behaviour), and Level 4 (results).

\section{References}

Aguinis, H., \& Kraiger, K. (2009). Benefits of training and development for individuals and teams, organisations, and society. Annual Review Psychology, 60, 451 - 474

Anderson, V. (2004). Research methods in human resource management. London: CIPD.

Armstrong, M. (2001). A handbook of human resource management practice (8th ed.). London: Kogan Page.

ASTD. (1997). The 1997 State of the industry report. Alexandria, VA: ASTD.

ASTD. (2007). The 2007 State of the industry report. Alexandria, VA: ASTD.

Barber, J. (2004). Skills upgrading within informal training: Lessons from the Indian Auto Mechanic. International Journal of Training, 8, $128-139$

Bee, F; \& Bee, R. (2003). Learning needs analysis and evaluation (2nd ed.). London: CIPD.

Brinkerhoff, O.B., \& Apking, A.M. (2001). High impact learning. Cambridge, MA: Perseus Publishing

Broad, M. L., \& Newstrom, J. W. (1992). Transfer of training: Action-packed strategies to ensure payoff from training investment. New York, NY: Addison-Wesley.

Buckley, R., \& Caple, J. (2007). The theory \& practice of training (5th ed.). London: Kogan Page.

Burden, R., \& Proctor, T. (2000). Creating a sustainable competitive advantage through training. Team Performance Management, 6(5), 90 - 97.

Chiaburu, D. S., \& Tekleab, A. G. (2005). Individual and contextual influences on multiple dimension of training effectiveness. Journal of European Industrial Training, 29(8), $604-626$.

Colquitt, J. A., LePine, J. A., \& Noe, R. A. (2000). Toward an integrative theory of training motivation: A metaanalytic path analysis of 20 years of research. Journal of Applied Psychology, 85, 678 - 707.

Creswell, J. W. (2008). Educational research: Planning, conducting, and evaluating quantitative and qualitative research (3rd ed.). Mason, OH: Prentice-Hall.

Dowling, P. J., \& Welch, D. E. (2004). International human resource management (4th ed.). London: Thomson South-Western.

Fink, A. (2009). How to conduct surveys: A step-by-step guide (4th ed.). London: Sage

Ford, J. K., \& Kraiger, K. (1995). The application of cognitive constructs and principles to the instructional systems design model of training: Implications for needs assessment, design, and transfer. International Review of Industrial and Organisational Psychology, 10, 1-48.

Goldstein, I. L., \& Ford, J. K. (2002). Training in organisations (4th ed.). Belmont, CA: Wadsworth Group.

Gómez-Mejía, L. R., Balkin, D. B., \& Cardy, R. L. (2010). Managing human resources (6th ed.). Mason, OH: PrenticeHall.

Hale, J. (2002). Performance-based evaluation: Tools and techniques to measure the impact of training. San Francisco, CA: Jossey-Bass

Hill, C. H., \& Lent, R. W. (2006). A narrative and meta-analytic review of helping skills training: Time to revive a dormant area of inquiry. Psychotherapy: Theory, Research, Practice, Training 43(2), 154-172.

Holton, E., \& Baldwin, T. T. (Eds.) (2003). Improving learning transfer in organisations. San Francisco, CA: John Wiley \& Sons 
Hughey, A. W., \& Mussnug, K. J. (1997). Designing effective employee training in Malaysia. International Review of Business Research Papers, 3(3),

Jamil, R., \& Som, H. (2007). Training needs analysis: Practices of top companies in Malaysia. International Review of Business Research Papers, 3(3), 162 - 175.

Kearns, P. (2000). Maximising your ROI in training: Delivering measurable added value through employee development. Harlow: Pearson Education.

Kirkpatrick, D. L. (1994). Evaluating training programs: The four levels. San Francisco, CA: Berrett-Koehler.

Kirkpatrick, D. L., \& Kirkpatrick, J. D. (2007). Implementing the four levels: A practical guide for effective evaluation of training programs. San Francisco, CA: Berrett-Koehler.

Kraiger, K., McLinden, D., \& Casper, W. J. (2004). Collaborative planning for training impact. Human Resources Management, 43(4), 337 - 351.

Kumar, R. (2005). Research methodology: A step-by-step guide for beginners (2nd ed.). London: Sage.

Lee, C.H., \&Bruvold, N.T. (2003). Creating value for employees: Investment in Lee, N., \& Lings, I. (2008). Doing business research: A guide to theory and practice. London: Sage.

McArdle, G. E. (2007). Training design and delivery (2nded.). Alexandria, VA: ASTD

McKenna, E., \& Beech, N. (2008). Human resource management: A concise analysis (2nd ed.). Harlow: PrenticeHall.

Merriam, S.B., \& Leahy, B. (2005). Learning Transfer: A review of the research in adult education and training. Journal of Lifelong Learning 14, 1 - 24.

Moskowitz, M. (2008).A practical guide to training and development: Assess, design, deliver, and evaluate. San Francisco, CA: John Wiley \& Sons.

Nickson, D. (2007). Human resource management for hospitality and tourism industries. Oxford: Elsevier.

Noe, R. A. (2005). Employee training and development (3rd ed.). Boston, MA: McGraw-Hill.

O’Leary, Z. (2004). The essential guide to doing research. London: Sage.

Opperman, C., \& Meyer, M. (2008). Integrating training needs analysis, assessment, and evaluation. Randburg: Knowres Publishing.

Paradise, A. (2008). 2008 State of the industry: ASTD's annual review of trends in workplace learning and performance. Alexandria, VA: ASTD.

Phillips, P. P., \& Stawarski, C. A. (2008). Data collection: Planning for and collecting all types of data. San Francisco, CA: John Wiley \& Sons programmes. Training for Quality, (2), 52 - 57.

Rothwell, W. J., \& Sredl, H. J. (Eds.) (1992). The ASTD reference guide to professional human resource development roles and competencies (2nd ed.) Alexandria, VA: ASTD.

Satterfield, M. J., \& Hughes, E. (2007). Emotional skills training for medical students: A systematic review. Medical Education 41, 935 - 941.

Swann Global (2009). 2009 Pan African total rewards study. Perth: Author.

Swanson, R. A., \& Holton, E. F. (2009). Foundations of human resource development (2nd ed.). San Francisco, CA: Berrett-Koehler Thomson Wadsworth.

Thorne, K., \& Machray, A. (2000). World class training: Providing training excellence. London: Kogan Page.

Torrington, D., Hall, J., \& Taylor, S. (2008). Human resource management (7th ed.). Harlow: Prentice-Hall.

Tracey, J. B., \& Tews, M. J. (2005). Construct validity of a general training climate scale. Organisational Research Methods, 8, $353-374$.

Tung-Chun, H. (2001). The relation of training practices and organisational performance in small and medium size enterprises.Education \& Training, 43(9), 437 - 444.

Van Buren, M. E., \& Erskine, W. (2002). State of the industry: ASTD's annual review of trends in employerprovided training in the United States. Alexandria, VA: ASTD. 
Eduku, f., \& Prah, E. A. (2015). Assesment of Traiing and Development Practices in Xyz Gold Mines Limited (Xyzgml) in Ghana. Advances in Social Sciences Research Journal, 2(10) 38-50.

Velada, R., \& Caetano, A. (2007). Training transfer: the mediating role of perception of learning. Journal of European Industrial Training, 31, 283-296.

Wall, T. D., Wood, S. J., \& Leach, D. J. (2004). Empowerment and performance.

Wang, L., \& Wentling, T. L. (2001). The relationship between distance coaching and the transfer of training. Baton Rouge, LA: Academy of Human Resources Development

Werner, J. M., \& DeSimone, R. L. (2006). Human resource development (4thed.).London: Thomson South-Western. White, A. (1998). The essential guide to developing your staff: How to recruit, train, coach, and mentor top-quality people. London: Judy Piatkus Limited.

XYZ Gold Mines Ltd. (2007). 2007 annual report. Littleton, CO: Author.

XYZ Gold Mines Ltd. (2008). 2008 annual report. Littleton, CO: Author. 